\title{
Genetic Variation Studies for Flower Production, Abscission and Pollen Load in Advanced Lines of Pigeonpea [Cajanus cajan (L.) Millsp.]
}

\begin{abstract}
Background: Flower bud/s, flower/s and fruit/pod/s abscission is one of the momentous bottlenecks in pulses in general and pigeonpea in particular, resulting in poor reproductive efficiency. Abscission occurs both before and after fertilization. Knowledge on nature and extent of genetic variation available in the genotypes help breeders for planning breeding programmes to identify genotypes that retain maximum flowers hence increase pod set.

Methods: A total of 19 advanced stabilized breeding lines including 2 local checks (GRG-811 and TS-3R) were evaluated in randomized block design (RBD) with two replications in rain fed and irrigated condition at Zonal Agricultural Research Station (ZARS), Kalaburagi, during kharif 2018. Genetic variation for flower production, abscission and pollen load were studied and interpreted.

Result: The genotypes viz., RIL-63, RIL-59, GRG-152 and KRG-224 showed good number of pods set per plant in rainfed condition and 3 Genotypes WRP-R-29-4, KRG-224 and ICPL-15017 in irrigated condition. The genotype KRG-224 Sets more pods under both conditions. Pollen grains load was more in undropped flower compared to dropped flower.
\end{abstract}

Key words: Floral abscission, Pollen load.

\section{INTRODUCTION}

Pigeonpea [Cajanus cajan (L.) Millsp.], one of the major pulse crops of the tropics and subtropics. Globally it is cultivated in about 7.02 million ha area with an annual production of 6.81 million tonnes and a mean productivity of $970 \mathrm{~kg} / \mathrm{ha}$ (FAOSTAT, 2019). India is the largest producer and consumer of pigeonpea with an area of $4.23 \mathrm{~m}$-ha, annual production of $3.89 \mathrm{~m}$-t and productivity of $919 \mathrm{~kg} / \mathrm{ha}$. In Karnataka an area of about 1.3 million hectares with production of 0.91 million tonne and productivity $700 \mathrm{~kg} / \mathrm{ha}$ (Annual Report AICRP on Pulses, 2020-21).

Pigeonpea flowers profusely during SeptemberOctober, a higher per cent of them abscise (70-96\%) without setting into pods. Grain yield depends upon percentage of flowers transforming into pods. Mineral nutrients are known to develop economic source-sink relationship in plants that ultimately increase the flower, fruit set and seed filling, there by increasing the yield. Pre-mature abscission of buds, flowers and fruits lead to reduced realization of sink potential. Thus, flower or fruit dropping is considered as a bottleneck in productivity.

Hence, it is very necessary to have a reliable data on the extent of abscission, its impact on yield and the ways to compensate the high degree of floral abscission by decrease in floral abscission or increase in pod set. In the present study, investigation was carried out to analyse genotypic differences for floral abscission under rainfed and irrigated condition.

\section{MATERIALS AND METHODS}

Investigation was carried out during Kharif 2018 at Zonal Agriculture Research Station, Kalaburagi which belongs to
Department of Genetics and Plant Breeding, College of Agriculture, University of Agricultural Sciences, Raichur-584 101, Karnataka, India.

Corresponding Author: Mahmadshafi, Department of Genetics and Plant Breeding, College of Agriculture, University of Agricultural Sciences, Raichur-584 101, Karnataka, India.

Email: mahmadshafi7886@gmail.com

How to cite this article: Mahmadshafi, Muniswamy, S., Khan H., Girish, G., Ravikumar, R. and Suma, T.C. (2022). Genetic Variation Studies for Flower Production, Abscission and Pollen Load in Advanced Lines of Pigeonpea [Cajanus cajan (L.) Millsp.]. Legume Research. DOI: 10.18805/LR-4692.

Submitted: 09-06-2021 Accepted: 01-11-2021 Online: 18-01-2022

the Agro-climatic zone-2 (North Eastern Dry Zone) of Karnataka state, India. The experimental material consists of 19 pigeonpea genotypes including two check varieties (TS-3R, GRG-811) which were obtained from ZARS, Kalaburagi. The full set of 19 genotypes including two checks were used to study flower production, buds, flowers, pods abscission and pod set in rainfed and irrigated condition.

The experimental block was divided into two separate plots, one plot as a rainfed condition without the supplementary irrigation and other plot with supplementary irrigation at different crop growth stages. 1 irrigation was given at vegetative stage to rainfed genotypes, where as 3 irrigations were given at vegetative, flowering and pod filling stage to irrigated genotypes. The experiment for floral abscission study was laid out in randomized block design (RBD) with 2 replications. Each genotype was sown in single 
row with spacing of $120 \mathrm{~cm}$ between the rows and $60 \mathrm{~cm}$ between the plants. Wide spacing would make the collection of dropped flower/s and /or pod/s convenient. Three plants were randomly selected in each treatment to study the flower production and buds, flowers and pods abscission.

Flowers drop $(\%)=$

$$
\frac{\text { No. of flowers dropped per plant }}{\text { Total no. of flowers produced per plant }} \times 100
$$

Pod set $(\%)=\frac{\text { No. of mature pod per plant }}{\text { Total no. of flowers produced per plant }} \times 100$

Total no. of flowers produced = Summation of buds dropped, flowers dropped, pods dropped and pods set on the plant. Total no. of flowers dropped $=$ Total number of flowers dropped in each genotype manually collected, counted and averaged. Total no. of pods dropped $=$ Total number of premature pods dropped in each genotyp were manually collected, counted and average.

Collected normal and abscised or dropped flowers from pigeonpea plant. The floral parts were dissected with the help of needles and forceps and anthers of normal and dropped flowers were separately collected on fresh slide, added 2-3 drops of 2\% acetocarmine solution to each slide containing anthers. The collected anthers were crushed thoroughly using blunt end of needle, so that pollen grains are released. The debris were removed from the slide with help of forcep and immediately cover slip was kept to prevent the entry of air bubble, after few second, the pollen grain load was observed in normal and abscised flowers per $\mathrm{cm}^{2}$ with the help of light microscope having high resolution 100x, for clear visibility.

\section{RESULTS AND DISCUSSION}

The analysis of variation shown highly significant differences in their mean performance among the genotypes studied under rainfed and irrigated condition (Table 1).

\section{Total number of flowers produced}

Wide range of flowers produced from 816.08 (RIL-63) to 2194.21 (GRG-177) with mean value of 1510.54. under rainfed condition, moderate GCV (19.19\%) and high PCV (26.24\%) were observed with moderate heritability of $(57.57 \%)$, high GA of $(470.10 \%)$ and high GAM of $(31.12 \%)$. The results were in agreement with Kulkarni et al. (2019) (Table 2, 3 and 4).

Under irrigated condition ranged from 748.67 (RIL-63) to 3080.00 (GPT-1) with mean value of 1685.57 . There was moderate GCV (28.66) and high PCV (30.64) were observed with high heritability of $87.49 \%$, high GA of $930.74 \%$ and high GAM of $55.22 \%$. High heritability $(57.57 \%)$ with high GAM $(31.12 \%)$ is suggestive of high response to appropriate selection procedures and thus selection for this trait will result in high genetic gain.

\section{Total number of buds dropped}

The buds dropped under rainfed condition showed wide variations ranging from 46.00 (RIL-63) to 206.67 (GRG-177)

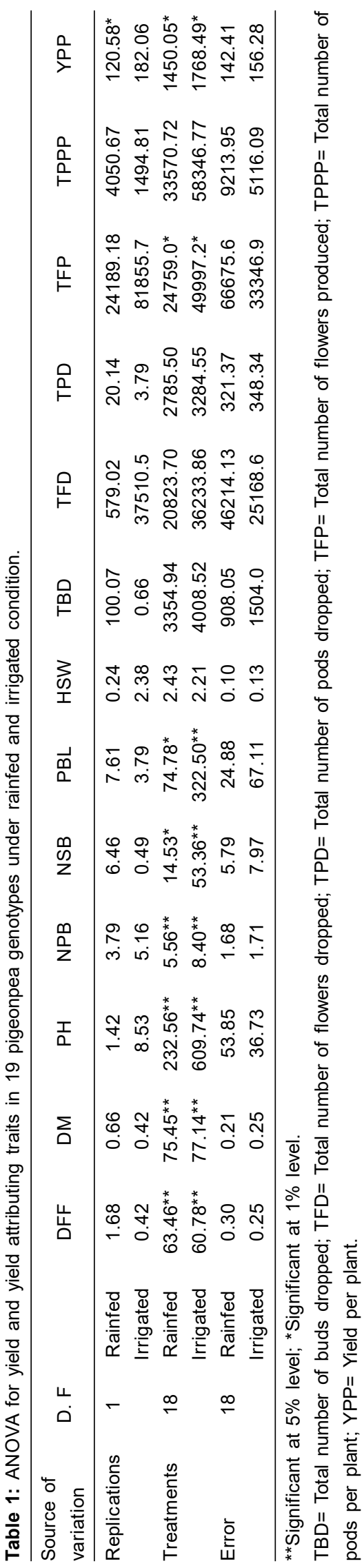


with mean of 127.80. High GCV (27.37\%) and PCV (36.13\%) with moderate heritability of $57.40 \%$, high GA of $54.59 \%$ and high GAM of $42.72 \%$.

In irrigated situation it was ranged from 42.67 (RIL-63) to 265.83 (GRG-177) with mean of 149.82. High GCV $(31.68 \%)$ and PCV $(40.91 \%)$ with moderate heritability of $59.96 \%$, high GA of 75.70 and high GAM of $50.53 \%$. Genotype RIL-63, reported a less number of buds drop in both situations. Hence, it can be further tested and can be utilized in the breeding programme.

Total number of buds, flowers and pods dropped in the entries investigated ranged from 308.25 (RAJA) to 12195.0 (GRG-177) with mean value of 4121.82 . The GCV and PCV were as high as 59.32 and $62.30 \%$ respectively with high heritability of $90.67 \%$, higher GA of $4796.81 \%$ and GAM of $116.38 \%$, reported by Kulkarni et al. (2019).

Total number of flowers dropped

Rainfed condition flower dropped ranged from 474.00 (RIL-63) to 1565.33 (GRG-177) with mean value of 1004.71 . The high GCV $24.58 \%$ and PCV $32.59 \%$ with moderate heritability of $56.90 \%$, high GA of $383.81 \%$ and high GAM of $38.20 \%$.

Irrigated condition ranged from 494.67 (RIL-63) to 2433.50 (GPT-1) with mean value of 1164.84 . The GCV $(35.25 \%)$ and PCV (37.79\%) high. with high heritability of $87.01 \%$, higher GA of 788.97 and high GAM of $67.73 \%$. PCV slightly higher then the GCV Which shows that the presence of environment effect on this trait.

In rainfed genotype RIL-59 showed the lowest flower drop $(52.20 \%)$ and in irrigated condition KRG-224 showed the lowest flower drop (56.42\%). Large genotypic variations were found with respect to flower drop in all the genotype under both the situations.

The highest flower drop could be due to internal hormonal changes like ABA (Abscissic acid), Ethylene, Proline, etc. and external factors like moisture content, availability of nutrients at flowering and pod filling stages (Gagandeep, 2014) pest and diseases, source to sink relationship, photosynthetic rate, sometimes pollen viability etc.

The genotypes viz., KRG-155, RIL-59, KRG-224, GRG222 showed less flower drop irrespective of situation, can be considered as stable genotype for the pod set. However, large differences have been noticed in the genotypes like GPT-1, GRG-177, GRG-222, GRG-224, KRG-244, KRG251, JSA-59-2, GRG-811 and RIL-59 under both condition.

GRG-177 showed the highest flower drop (93.06\%) and genotype RAJA showed the lowest flower drop (27.11\%), Genotypes RAJA, GRG-2013, ICP-11320 and BAHAR showed lesser flower produced to pod set ratio indicating a greater number of pods set for total flowers produced and effective utilization of photosynthates. Observed by Kulkarni et al. (2019).

Total number pods dropped

Pods dropped in rainfed condition ranged from 39.00 (RIL-63) to 115.33 (KRG-244) with mean value of 85.57 . There was 
Genetic Variation Studies for Flower Production, Abscission and Pollen Load in Advanced Lines of Pigeonpea [Cajanus cajan (L.) Millsp.]

Table 3: Genotypic variation for flower production and abscission in pigeonpea genotypes under rainfed condition.

\begin{tabular}{|c|c|c|c|c|c|c|c|c|}
\hline Genotypes & $\begin{array}{c}\text { Total number } \\
\text { of flowers } \\
\text { produced }\end{array}$ & $\begin{array}{l}\text { Total number } \\
\text { of buds } \\
\text { dropped }\end{array}$ & $\begin{array}{l}\text { Total number } \\
\text { of flowers } \\
\text { dropped }\end{array}$ & $\begin{array}{l}\text { Total number } \\
\text { of pods } \\
\text { dropped }\end{array}$ & $\begin{array}{l}\text { Total number } \\
\text { of pods } \\
\text { produced }\end{array}$ & $\begin{array}{c}\% \\
\text { flower } \\
\text { dropped }\end{array}$ & $\begin{array}{c}\% \\
\text { pod } \\
\text { set }\end{array}$ & $\begin{array}{c}\text { Flower produced } \\
\text { to pod } \\
\text { set ratio }\end{array}$ \\
\hline GRG-152 & 1847.50 & 100.34 & 1104.50 & 94.00 & 548.67 & 60.11 & 29.14 & $3.4: 1$ \\
\hline GRG-177 & 2194.21 & 174.54 & 1565.33 & 102.83 & 351.50 & 70.02 & 17.47 & $6.3: 1$ \\
\hline GRG-222 & 1703.88 & 110.71 & 1100.83 & 70.83 & 421.50 & 64.21 & 24.73 & 4.0:1 \\
\hline GRG-617 & 1222.81 & 109.81 & 793.00 & 68.83 & 251.17 & 64.54 & 20.76 & 4.9:1 \\
\hline KRG-224 & 888.51 & 73.84 & 493.83 & 74.17 & 246.67 & 56.69 & 26.63 & $4.5: 1$ \\
\hline KRG-33 & 1580.84 & 162.85 & 1105.50 & 101.17 & 211.33 & 69.79 & 13.42 & $7.5: 1$ \\
\hline KRG-221 & 1423.94 & 80.61 & 1053.00 & 109.83 & 180.50 & 73.95 & 12.65 & 7.9:1 \\
\hline KRG-244 & 1313.06 & 99.23 & 789.50 & 115.33 & 309.00 & 60.16 & 23.54 & $4.2: 1$ \\
\hline KRG-155 & 1648.11 & 142.11 & 1010.17 & 80.50 & 415.33 & 61.36 & 25.11 & $4.0: 1$ \\
\hline KRG-251 & 1534.16 & 102.99 & 1141.67 & 91.00 & 198.50 & 74.16 & 13.13 & $7.7: 1$ \\
\hline AGL-1603-2 & 1690.40 & 147.24 & 1200.33 & 93.50 & 249.34 & 71.03 & 14.78 & 6.9:1 \\
\hline WRP-R-29-4 & 1753.16 & 121.33 & 1152.00 & 95.83 & 384.00 & 65.78 & 21.95 & $4.6: 1$ \\
\hline JSA-59-2 & 1352.97 & 133.47 & 957.00 & 75.17 & 187.34 & 71.03 & 13.47 & $7.2: 1$ \\
\hline GPT-1 & 1764.50 & 113.67 & 1299.50 & 87.00 & 264.33 & 74.32 & 13.89 & $6.7: 1$ \\
\hline ICPL-15017 & 1392.47 & 61.31 & 914.00 & 70.17 & 347.00 & 65.59 & 24.96 & $4.0: 1$ \\
\hline TS-3R & 1955.22 & 140.05 & 1397.67 & 113.67 & 303.84 & 71.68 & 15.08 & $6.4: 1$ \\
\hline GRG-811 & 1547.89 & 151.73 & 983.83 & 86.17 & 326.17 & 63.54 & 21.09 & $4.7: 1$ \\
\hline RIL-59 & 1070.64 & 122.80 & 553.83 & 56.83 & 337.17 & 52.20 & 31.28 & $3.2: 1$ \\
\hline RIL-63 & 816.08 & 45.75 & 474.00 & 39.00 & 257.33 & 58.05 & 31.53 & $3.2: 1$ \\
\hline Overall mean & 1510.54 & 115.49 & 1004.71 & 85.57 & 304.77 & 65.70 & 20.77 & \\
\hline SD & 351.85 & 34.35 & 290.03 & 19.82 & 94.15 & & & \\
\hline
\end{tabular}

Table 4: Genotypic variation for flower production and abscission in pigeonpea genotypes under irrigated condition.

\begin{tabular}{|c|c|c|c|c|c|c|c|c|}
\hline Genotypes & $\begin{array}{c}\text { Total number } \\
\text { of flowers } \\
\text { produced }\end{array}$ & $\begin{array}{l}\text { Total number } \\
\text { of buds } \\
\text { dropped }\end{array}$ & $\begin{array}{l}\text { Total number } \\
\text { of flowers } \\
\text { dropped }\end{array}$ & $\begin{array}{c}\text { Total number } \\
\text { of pods } \\
\text { dropped }\end{array}$ & $\begin{array}{c}\text { Total number } \\
\text { of pods } \\
\text { produced }\end{array}$ & $\begin{array}{c}\% \\
\text { flower } \\
\text { dropped }\end{array}$ & $\begin{array}{c}\% \\
\text { pod } \\
\text { set }\end{array}$ & $\begin{array}{c}\text { Flower produced } \\
\text { to pod } \\
\text { set ratio }\end{array}$ \\
\hline GRG-152 & 1214.50 & 107.33 & 826.17 & 101.17 & 179.84 & 68.10 & 14.77 & $6.8: 1$ \\
\hline GRG-177 & 2448.50 & 265.83 & 1835.00 & 135.50 & 212.17 & 74.73 & 8.84 & 11.5: 1 \\
\hline GRG-222 & 1569.34 & 155.17 & 986.00 & 80.83 & 347.34 & 62.46 & 22.38 & 4.5: 1 \\
\hline GRG-617 & 1478.00 & 117.17 & 944.83 & 79.00 & 337.00 & 63.54 & 22.92 & 4.4: 1 \\
\hline KRG-224 & 1265.84 & 78.50 & 714.67 & 59.50 & 413.17 & 56.42 & 32.70 & 3.1: 1 \\
\hline KRG-33 & 1571.50 & 188.00 & 1117.50 & 98.00 & 344.34 & 73.02 & 23.34 & 4.6: 1 \\
\hline KRG-221 & 1618.17 & 189.17 & 1051.83 & 117.50 & 210.34 & 65.02 & 12.87 & 7.8: 1 \\
\hline KRG-244 & 1765.00 & 210.67 & 1211.83 & 135.67 & 222.84 & 68.68 & 12.56 & 8.6: 1 \\
\hline KRG-155 & 1458.83 & 172.17 & 915.33 & 123.67 & 194.33 & 62.72 & 13.31 & 7.5: 1 \\
\hline KRG-251 & 1975.83 & 217.17 & 1411.83 & 154.67 & 199.17 & 71.38 & 10.09 & 9.9: 1 \\
\hline AGL-1603-2 & 1866.00 & 154.50 & 1367.33 & 97.50 & 292.33 & 73.31 & 15.67 & $6.4: 1$ \\
\hline WRP-R-29-4 & 1627.66 & 97.83 & 1011.33 & 85.17 & 535.50 & 62.24 & 32.89 & 3.1: 1 \\
\hline JSA-59-2 & 1893.17 & 108.67 & 1195.17 & 75.67 & 501.00 & 63.11 & 26.43 & 3.8: 1 \\
\hline GPT-1 & 3552.34 & 203.67 & 2433.50 & 211.00 & 853.34 & 68.79 & 23.96 & 4.2: 1 \\
\hline ICPL-15017 & 1389.00 & 119.00 & 1029.83 & 84.50 & 445.67 & 73.84 & 31.87 & 3.4: 1 \\
\hline TS-3R & 1947.33 & 117.17 & 1281.83 & 84.83 & 352.67 & 65.91 & 18.11 & 5.5: 1 \\
\hline GRG-811 & 1933.83 & 156.83 & 1393.83 & 90.00 & 241.84 & 72.16 & 12.53 & 8.0: 1 \\
\hline RIL-59 & 1342.67 & 145.00 & 909.50 & 57.83 & 206.50 & 68.07 & 15.83 & 6.5: 1 \\
\hline RIL-63 & 748.67 & 42.67 & 494.67 & 27.67 & 159.33 & 66.22 & 21.38 & 4.7: 1 \\
\hline Overall mean & 1719.27 & 149.82 & 1164.84 & 99.98 & 328.88 & 67.35 & 19.60 & \\
\hline SD & 575.04 & 54.81 & 425.64 & 40.53 & 169.64 & & & \\
\hline
\end{tabular}


moderate GCV (17.80\%) and high PCV (27.49\%) was reported. with moderate heritability of $67.93 \%$, high GA of $20.32 \%$ and high GAM of $23.75 \%$.

Under irrigated condition ranged from 27.67 (RIL-63) to 211.00 (GPT-1) with mean value of 99.98 . The GCV and PCV were recorded to be high $38.32 \%$ and $42.63 \%$ respectively with high heritability of $80.82 \%$, high GA of $70.96 \%$ and high GAM of $70.97 \%$. The results were in agreement with Kulkarni et al. (2019).

\section{Total number of pods per plant}

Total number of pods per plant under rainfed condition ranged from 180.50 (KRG-221) to 548.67 (GRG-152) with mean of 305.48 . The GCV and PCV were high i.e., $27.73 \%$ and $41.91 \%$ respectively with moderate heritability of $63.79 \%$, high GA and GAM of $115.50 \%$ and $37.81 \%$ respectively.

Under irrigated condition ranged from 159.50 (RIL-63) to 853.33 (GPT-1) with mean of 327.83. GCV and PCV were high i.e., $49.76 \%$ and $54.34 \%$ respectively with high heritability of $83.88 \%$, high GA and GAM of $307.79 \%$ and $93.89 \%$.

The genotypes expressing higher number of pods set per cent are considered to have high reproductive efficiency. This higher efficiency can be utilized to improve the yield of pigeonpea.

Rainfed condition genotypes RIL-63, RIL-59, GRG-152, KRG-224 and in irrigated condition genotypes like WRP-R29-4, ICPL-15017, KRG-224 and JSA-59-2 showed higher number of pods per plant. Higher number of pods per plant indicating their high reproductive efficiency. Results are in agreement with previous studies conducted by Kulkarni et al. (2019), Sarsamkar et al. (2008), Vange and Egbe (2009), Bhadru (2011), Sharma et al. (2012) and Rao et al. (2013) whereas, Vanisree et al. (2013) and Yogendra et al. (2013) obtained low heritability. Muniswamy et al. (2014) and Singh et al. (2018) obtained high GCV, PCV, heritability and GAM.

\section{Flower produced to pod set ratio}

Genotype KRG-221 showed the highest flower produced to pod set ratio $(7.9: 1)$ in rainfed and in irrigated condition genotype GRG-177 showed highest flower produced to pod ratio of (11.5:1) which indicated that out of 7.9 flowers in rainfed and 11.5 in irrigation condition are required to produce one pod. But the genotypes KRG-224 and WRPR-29-2 showed lowest flower produced to pod set ratio (3.1:1) in irrigated condition and genotype RIL-59 and RIL63 reported lowest flower produced to pod set ratio (3.2:1) in rainfed condition which indicates reproductive efficiency of the genotypes. Similar results were obtained by Kulkarni et al. (2019).

This genetic variation is due to differential response of genotypes to source and sink relationship. The character flower production and abscission showed high heritability indicating genetic governance of the trait. The genotypes which are contrasting for this trait can be further used to study the number of genes governing the floral abscission. The genotypes with more floral abscission and fewer pod set shows their reproductive inefficiency in terms of improper use of photosynthates. In contrast, the genotypes with less floral abscission and more pod set are preferred as they exhibit high reproductive efficiency without wasting photosynthates of plant. The genotypes KRG-224, WRP-R-29-2, RIL-59 and RIL-63 were found to be good reproductive efficiency. Details given in Table 3 and 4 .

Pollen load study reveals that number of pollen grains in each six microscopic field with $1 \mathrm{~cm}^{2}$ area, in normal flower was $27,19,21,14,18$ and 19. Hence, the average pollen load per microscopic field is 19.7. Where as in abscised flowers the pollen load was $10,7,9,12,7$ and 8 and average pollen load for each microscopic field was 8.9. The observation revealed that more load of pollens in normal flower compared to pollen grain in abscised flower. Reviews were not available for this study indicating its novelty. Given in Plate I and II.

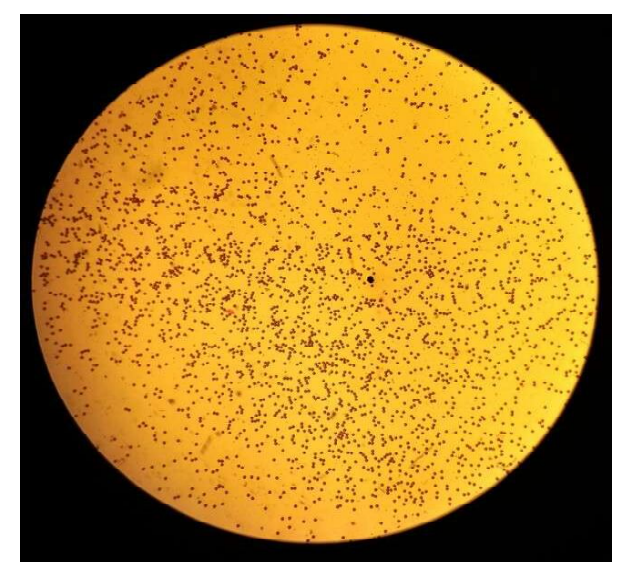

Plate I: Pollen load in Undropped flower.

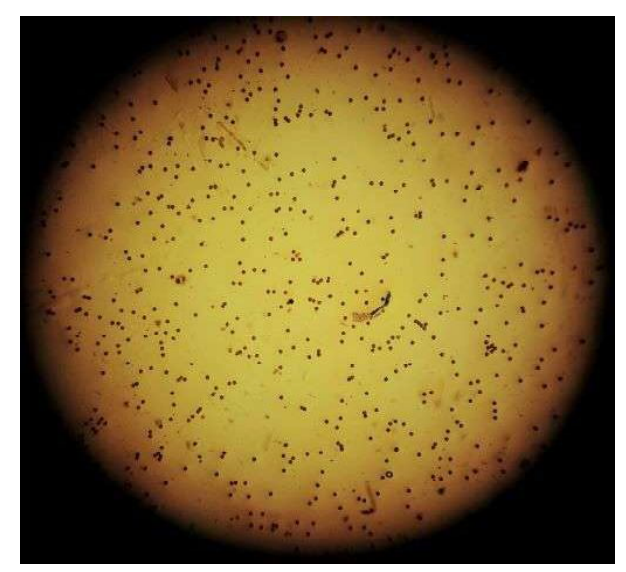

Plate II: Pollen load in dropped flower. 


\section{CONCLUSION}

The genotypes contrasting to the trait flower abscission like KRG-224, WRP-R-29-2, RIL-59 and RIL-63 can be used in crossing to identify number of genes governing the trait and developing mapping population.

The genotypes RIL-59, KRG-224, RIL-63, GRG-152, GRG-222, KRG-155, ICPL-15017 and KRG-244 showed highest pod set as indicated by flower produced to pod set ratio in rainfed condition and the genotype KRG-224, RIL59, KRG-244, KRG222, KRG-617, KRG-155 and WRP-R29-4 showed highest pod set as indicated by flower produce to pod set ratio in irrigated condition. These genotypes can be further tested and can be included in yield improvement programmes. The pollen grains load was more in undropped flower compared to dropped flower, indicating role of pollen grains load on fertilization which may be directly influenced on pod set.

\section{REFERENCES}

Bhadru, D. (2011). Research Note Genetic studies in pigeonpea [Cajanus cajan (L.) Mill sp]. Electronic Journal of Plant Breeding. 2(1): 132-134.

FAOSTAT, (2019). FAOSTAT Statistical Data Box.

Gagandeep, K. (2014). Physiological and anatomical basis of flower drop in pigeonpea (Cajanus cajan L.) in response to foliar application of mineral nutrients, Ph. D (Botany) Thesis, Punjab Agric. Univ., Ludhiana, Punjab (India).

Kulkarni, P., Muniswamy, S., Lokesha, R., Girish, G., Suma, T.C. and Mahaling, D. M. (2019). Floral Abscission in Pigeonpea [Cajanus cajan (L.) Millsp.]. Genotypic Disparity in Land Races, Hybrids and Advanced Breeding Lines. Int. J. Pure App. Biosci. 7(1): 389-397.
Muniswamy, S., Arunkumar, B. and Dharmaraj, P.S. (2014). Interpretation of genotypes $\times$ environment interaction and stability analysis for grain yield of pigeonpea [Cajanus cajan (L.) Millsp]. J. of App. and Natural Sci. 6(2): 744-747.

Project Coordinator's Report 2020-21, AICRP on Pigeonpea.

Rao, P.J.M., Upender, M. and Vijay, B.A. (2013). Variability and genetic diversity studies in redgram [Cajanus cajan (L.) Millsp.]. Int. J. App. Bio. Phar. Tech. 4(4): 48-51.

Sarsamkar, S.S., Borgaonkar, S.B., Kalyankar, S.V., Kadam, B.P. and Kadam, G.R. (2008). Genetic variability studies in pigeonpea [Cajanus cajan (L.) Millsp.]. Int. J. of Plant Sciences. 3(2): 502-503.

Sharma, M., Rathore, A., Mangala, U.N., Ghosh, R., Sharma, S., Upadhyay, H.D. and Pande, S. (2012). New sources of resistance to Fusarium wilt and sterility mosaic disease in a mini-core collection pigeonpea germplasm. European J. PI. Pathol. 133: 707-714.

Singh, G., Singh, I., Sharma, P., Gupta, M. and Singh, S. (2018). Devising selection criteria based on variability and association studies in segregating populations derived from an interspecific cross between Cajanus scarabaeoides $\times C$. cajan. Legume Research. 44(6): 615-620.

Vange, T. and Moses, E. (2009). Studies on genetic characteristics of pigeonpea germplasm. World J. Agric. Sci. 5(6): 714-719.

Vanisree, S., Sreedhar, M. and Raju, S. (2013). Studies on genetic characteristics of pigeonpea and determination of selection criteria with path co-efficient analysis. Int. J. App. Bio. Phar. Tech. 4(2): 223-226.

Yogendra, P., Kamaleshawar, K. and Mishra, S.B. (2013). Studies on genetic parameters and inter-relationships among yield and yield contributing traits in pigeonpea [Cajanus cajan (L.) Millsp.]. The Biosci. 8(1): 207-211. 